\section{Case Reports in Neurology}

Case Rep Neurol 2020;12:321-328

DOI: 10.1159/000511179

Published online: September 28, 2020

(C) 2020 The Author(s)

Published by S. Karger AG, Basel www.karger.com/crn

This article is licensed under the Creative Commons Attribution-NonCommercial 4.0 International License (CC BY-NC) (http://www.karger.com/Services/OpenAccessLicense). Usage and distribution for commercial purposes requires written permission.

\title{
COVID-19 Related Cerebrovascular Thromboembolic Complications in Three Young Patients
}

\author{
Khawaja Hassan Haroon ${ }^{a, b} \quad$ Ahmad Muhammad $^{a, b} \quad$ Suhail Hussain $^{a}$ \\ Satya Narayana Patro ${ }^{a, b}$ \\ aNeuroscience Institute, Hamad Medical Corporation, Doha, Qatar; ${ }^{b}$ Weill Cornell \\ Medicine-Qatar, Doha, Qatar
}

\section{Keywords}

Cerebral infarction · Cerebral venous thrombosis · COVID · Stroke · Thromboembolic complications

\begin{abstract}
Coronavirus disease 2019 (COVID-19) is a viral illness, caused by the novel severe acute respiratory syndrome-coronavirus-2 (SARS-CoV-2). It is currently affecting millions of people worldwide and is associated with coagulopathy, both in the venous and arterial systems. The proposed mechanism being excessive inflammation, platelet activation, endothelial dysfunction, and stasis. As an ongoing pandemic declared by WHO in March 2020, health systems worldwide are experiencing significant challenges with COVID-19-related complications. It has been noticed that patients with COVID-19 are at greater risk of thrombosis.
\end{abstract}

(C) 2020 The Author(s)

Published by S. Karger AG, Basel 


\section{Case Reports in Neurology}

Case Rep Neurol 2020;12:321-328

DOI: $10.1159 / 000511179$

(c) 2020 The Author(s). Published by S. Karger AG, Basel www.karger.com/crn

Haroon et al.: COVID-19-Related Cerebrovascular Thromboembolic Complications

\section{Introduction}

We describe clinical, radiological and laboratory findings of three young patients who presented with ischemic stroke and cerebral venous sinus thrombosis to our hospital within the first few weeks of COVID-19 outbreak. These patients were tested positive for COVID-19 (confirmed by reverse-transcriptase PCR).

\section{Case Presentation}

Case 1

A 47-year-old Indian man was brought to the emergency department as he was found on the floor with left-sided weakness and a reduced level of consciousness of an unknown time of onset. He had no past medical history. His vitals were stable apart from a respiratory rate of 25/min. His CT of the brain, CT angiogram and CT perfusion (Fig. 1a-e) showed acute established infarct in the right frontal lobe and basal ganglia, large matched defect in the right MCA territory and occlusion of right CCA and right terminal ICA with no evidence of dissection as well as lung findings suggestive of COVID-19 pneumonia. Considering the unclear time of onset and the already established large infarct, he was deemed unsuitable for acute reperfusion therapies.

His COVID-19 PCR was positive. The D-dimer level was $1.23(0-0.49)$ and the fibrinogen level was 6.9 (2-4.1). FBC showed Hb 11.1 (13-17) with platelets 531 (150-400); renal functions and electrolytes were all normal; CRP level was 42 (0-5) and ferritin 235 (48-420). He was diagnosed as newly diabetic with $\mathrm{Hb}_{\mathrm{A} 1 \mathrm{c}} 13.1 \mathrm{mmol} / \mathrm{L}$.

Over the next $24 \mathrm{~h}$, his conscious level deteriorated with further worsening of the focal neurological deficit and homonymous hemianopia. He was transferred to medical ICU for close monitoring and his follow-up non-contrast CT of the head (Fig. 1f) revealed large right MCA territory infarct. Seven-day cardiac monitoring in medical ICU did not reveal paroxysmal AF.

He started to have temperature spikes of up to $39^{\circ} \mathrm{C}$ on day 4 of admission. He was treated for COVID-19 mild pneumonia as per our protocol and standard treatment for acute ischemic stroke. He was started on aspirin and atorvastatin. A VTE prophylactic dose of enoxaparin 40 mg was given. His ECG and echocardiography were essentially normal with normal thrombophilia screen.

On day 10, he was found to have right leg swelling. Doppler US of the leg confirmed proximal right lower limb DVT. Initially, he was treated with treatment dose of LMWH followed by dabigatran $150 \mathrm{mg}$ b.i.d. Later, he was transferred to a rehabilitation facility.

Case 2

A 32-year-old obese man of Cameroonian origin with no past medical history was admitted with a 4-day history of fever, headache, sore throat and dry cough. His temperature was $39^{\circ} \mathrm{C}$ with a respiratory rate of $16 / \mathrm{min}$, oxygen saturation of $94 \%$ on room air and blood pressure of $126 / 76$. Chest X-ray showed lower zone pneumonic consolidation. Nasopharyngeal swab for COVID-19 PCR was positive. He was treated as COVID-19 pneumonia as per our local guidelines. He was given enoxaparin $60 \mathrm{mg}$ for VTE prophylaxis (modified regimen because of obesity as per protocol). As the patient was stable, he was transferred to a community hospital. 


\section{Case Reports in Neurology}

Case Rep Neurol 2020;12:321-328 DOI: 10.1159/000511179

2020 The Author(s). Published by S. Karger AG, Basel www.karger.com/crn

Haroon et al.: COVID-19-Related Cerebrovascular Thromboembolic Complications

Thirteen days after COVID-19 symptoms onset, he developed facial weakness with severe dysarthria and right-sided weakness with power $1 / 5$ in the upper limb and $4 / 5$ in the lower limb. He was transferred to a stroke center where the CT of the head, perfusion and angiogram (Fig. 2a-d) showed early ischemic changes in the left posterior parietal lobe, matched defect in the same area and patent intracranial arteries. Due to delayed presentation and established infarcted area on scans, he was not thrombolyzed. MRI of the head and MRA of the neck (Fig. $2 \mathrm{e}-\mathrm{h}$ ) revealed multiple infarcts in the left frontoparietal lobe, likely representing embolic etiology and moderate to severe stenosis in the left distal cavernous ICA, respectively.

His CRP was 129 (0-5) with normal renal, liver functions, electrolytes, lipid profile and glucose. D-dimer and fibrinogen levels were $0.72(0-0.49)$ and $4.8(2-4.1)$, respectively. Young stroke screen including thrombophilia screen were negative. His 72-h cardiac monitoring as an inpatient did not show evidence of paroxysmal AF.

His ECG was normal with normal TTE and contrast echo study. He was started on aspirin $100 \mathrm{mg}$, clopidogrel $75 \mathrm{mg}$, and atorvastatin $40 \mathrm{mg}$ per day. He was managed for COVID-19 as per our local protocol. He had regular rehabilitation and was discharged home with minimal weakness.

Case 3

A 30-year-old Nepalese man was brought to the emergency department as he had occipital headache for 4 days followed by a 2-day history of mild left arm weakness. His weakness got worse in the last $24 \mathrm{~h}$ prior to admission. On examination, his left arm power was $3 / 5$ with persistent headache. He also had a mild cough for 3 days. His CT of the head (Fig. 3a) revealed hemorrhagic infarcts in the right high frontal lobe which also raised suspicion of CVST. MRI of the head and MRV (Fig. 3b-h) showed venous infarct in the right high frontal lobe, thrombus in the superior sagittal sinus as well as non-visualization of superior sagittal and right transverse sinuses.

His thrombophilia screen, including lupus anti-coagulant and anticardiolipin antibodies, was normal. His nasopharyngeal swab for COVID was positive with normal chest X-ray. His D-dimer level was $1.02(0-0.49)$ and CRP level was $19(0-5)$ with normal routine labs including lipid profile and glucose.

He was initially treated with a treatment dose of LMWH. Later, he was started on rivaroxaban $15 \mathrm{mg}$ b.i.d. for 3 weeks followed by $20 \mathrm{mg}$ daily for 3 months with the plan to repeat MRV in 3 months' time. He was classed as COVID-19 LRTI and was managed as per our local guidelines.

\section{Discussion}

SARS-CoV-2 is a single-stranded RNA coronavirus, which enters human cells mainly by binding the angiotensin-converting enzyme 2 [1], which is highly expressed in lung alveolar cells, cardiac myocytes, the vascular endothelium, and other cells [2, 3].

SARS-CoV-2-mediated disruption and damage to the endothelium may be playing a key role in thrombus formation in patients with COVID-19, as recently, viral particles have been identified in systemic endothelia along with accumulations of inflammatory cells and apoptosis (endotheliitis) [4, 5]. SARS-CoV-2 infection is also linked to a prothrombotic state causing venous and arterial thromboembolism and elevated D-dimer levels [6].

All our patients had standard serological tests and coagulation markers checked at our organization for SARS-CoV-2-positive cases. All three patients had raised D-dimers and CRP. 


\section{Case Reports in Neurology}

Case Rep Neurol 2020;12:321-328

DOI: 10.1159/000511179 (c) 2020 The Author(s). Published by S. Karger AG, Basel www.karger.com/crn

Haroon et al.: COVID-19-Related Cerebrovascular Thromboembolic Complications

Notably, our first patient had both arterial as well venous thrombosis. All our three patients are young and had negative thrombophilia tests. Patients 1 and 2 did not show evidence of cardiac thromboembolism as echocardiograms were unremarkable and without evidence of patent foramen ovale. Their inpatient cardiac monitoring did not reveal evidence of paroxysmal AF.

Our first patient had mild to moderate SARS-CoV-2 infection, while the second and third patients had mild SARS-CoV-2 infection. Interestingly, our first and third patients presented with stroke at the onset of COVID-19 infection while the second patient developed stroke 2 weeks after onset of COVID-19 symptoms, suggesting that COVID-19-associated thromboembolism can occur both early and later in the course of the disease.

Recently, three main mechanisms, including hypercoagulopathy, vasculitis and cardiomyopathy leading to stroke in COVID-19 patients, have been described, while the role of various vascular and immune-mediated factors in the pathogenesis of stroke in these patients remain unclear [7]. Our first and second patient showed significant arterial lesions, while the third patient showed a high burden of cerebral venous sinus thrombosis with raised D-dimers and inflammatory markers, leading to stroke.

Initial CTA of the second patient did not reveal a vascular lesion, which could be possibly obscured by the surrounding bones and other structures in that particularly tight and small portion of cavernous ICA. His MRA of the neck showed significant disease in that portion of the ICA.

Our first patient showed an extensive thrombus in an atypical location emanating from the common carotid artery to the terminal right ICA and the second patient revealed a significant localized intracranial lesion. It remains unclear whether such large lesions are formed at the site or are embolic in nature [7]. As there is no other explanation for such lesions in our previously healthy and young patients, we hypothesize that SARS-CoV-2 possibly led to significant local inflammation and thrombus formation.

Though elderly and people with comorbidities such as cardiovascular disease are at higher risk for severe disease, young and otherwise healthy patients are also at risk for complications [8]. All our three patients were previously healthy without known chronic health conditions. Our first patient had T2DM diagnosed during admission.

There have been case reports of large vessel arterial thrombosis in mild COVID-19 cases with the youngest being a 33-year-old female $[9,10]$. Our second and third patients were 32 and 30 years old, respectively. Our second patient was treated with dual antiplatelets in view of a lesion in the left distal cavernous ICA as intracranial symptomatic disease and continued for 3 months [11]. Though challenging, all our patients were treated with anti-thrombotics and investigated as deemed appropriate by the treating clinicians.

\section{Conclusion}

Young cases with mild COVID-19 symptoms presenting with major cerebrovascular thrombotic lesions are unusual though evidence in this group is accumulating. Still, there remains uncertainty about the mechanisms and treatment options for stroke in COVID-19 patients. Future clinical trials are warranted to establish the mechanism and to determine the safety and efficacy of these different therapeutic options in patient with SARS-CoV-2 infection. 


\section{Case Reports in Neurology}

\begin{tabular}{l|l}
\hline Case Rep Neurol 2020;12:321-328 \\
\hline DOI: 10.1159/000511179 & $\begin{array}{l}\text { @ 2020 The Author(s). Published by S. Karger AG, Basel } \\
\text { www.karger.com/crn }\end{array}$ \\
\hline
\end{tabular}

Haroon et al.: COVID-19-Related Cerebrovascular Thromboembolic Complications

\section{Statement of Ethics}

This article was conducted ethically in accordance with the World Medical Association Declaration of Helsinki. The subject in this paper gave their written informed consent to publish their case including publication of images.

\section{Disclosure Statement}

The authors have no conflicts of interest to disclose.

\section{Funding Sources}

No funding.

\section{Authors Contributions}

Dr. Khawaja Hassan Haroon: Manuscript development, patient management, literature review, critical review.

Dr. Ahmad Muhammad: Manuscript development, literature review, critical review.

Dr. Suhail Hussain: Patient management and critical review.

Dr. Satya Narayana Patro: Images review and selection.

\section{References}

1 Walls AC, Park YJ, Tortorici MA, Wall A, McGuire AT, Veesler D. Structure, Function, and Antigenicity of the SARS-CoV-2 Spike Glycoprotein. Cell. 2020 Apr;181(2):281-292.e6.

2 Huang C, Wang Y, Li X, Ren L, Zhao J, Hu Y, et al. Clinical features of patients infected with 2019 novel coronavirus in Wuhan, China. Lancet. 2020 Feb;395(10223):497-506.

3 Zhang H, Penninger JM, Li Y, Zhong N, Slutsky AS. Angiotensin-converting enzyme 2 (ACE2) as a SARS-CoV-2 receptor: molecular mechanisms and potential therapeutic target. Intensive Care Med. 2020 Apr;46(4):58690.

4 Sardu C, Gambardella J, Morelli M, Wang X, Marfella R, Santulli G. Is COVID-19 an endothelial disease? Clinical and basic evidence. Preprints 2020, 2020040204. (doi: https://doi.org/10.20944/preprints202004.0204.v1.)

5 Varga Z, Flammer AJ, Steiger P, Haberecker M, Andermatt R, Zinkernagel AS, et al. Endothelial cell infection and endotheliitis in COVID-19. Lancet. 2020 May;395(10234):1417-8.

6 Tang N, Li D, Wang X, Sun Z. Abnormal coagulation parameters are associated with poor prognosis in patients with novel coronavirus pneumonia. J Thromb Haemost. 2020 Apr;18(4):844-7.

7 Spence JD, de Freitas GR, Pettigrew LC, Ay H, Liebeskind DS, Kase CS, et al. Mechanisms of Stroke in COVID19. Cerebrovasc Dis. 2020 2020;49(4):451-8.

8 Wu C, Chen X, Cai Y, Xia J, Zhou X, Xu S, et al. Risk factors associated with acute respiratory distress syndrome and death in patients with coronavirus disease 2019 pneumonia in Wuhan, China. JAMA Intern Med. 2020 Jul;180(7):934-43.

9 Fara MG, Stein LK, Skliut M, Morgello S, Fifi JT, Dhamoon MS. Macrothrombosis and stroke in patients with mild Covid-19 infection [ahead of print]. J Thromb Haemost. 2020 Aug;18(8):2031-3.

10 Oxley TJ, Mocco J, Majidi S, Kellner CP, Shoirah H, Singh IP, et al. Large-vessel stroke as a presenting feature of covid-19 in the young. N Engl J Med. 2020 May;382(20):e60.

11 Chimowitz MI, Lynn MJ, Derdeyn CP, Turan TN, Fiorella D, Lane BF, et al.; SAMMPRIS Trial Investigators. Stenting versus aggressive medical therapy for intracranial arterial stenosis. N Engl J Med. 2011 Sep;365(11):993-1003. 


\section{Case Reports in Neurology}

Case Rep Neurol 2020;12:321-328

DOI: $10.1159 / 000511179$

(c) 2020 The Author(s). Published by S. Karger AG, Basel www.karger.com/crn

Haroon et al.: COVID-19-Related Cerebrovascular Thromboembolic Complications
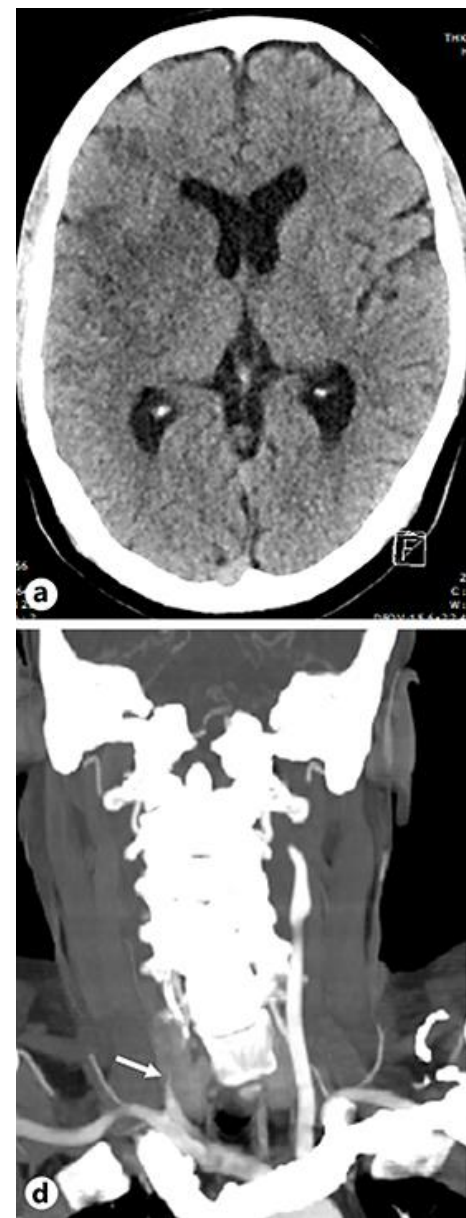
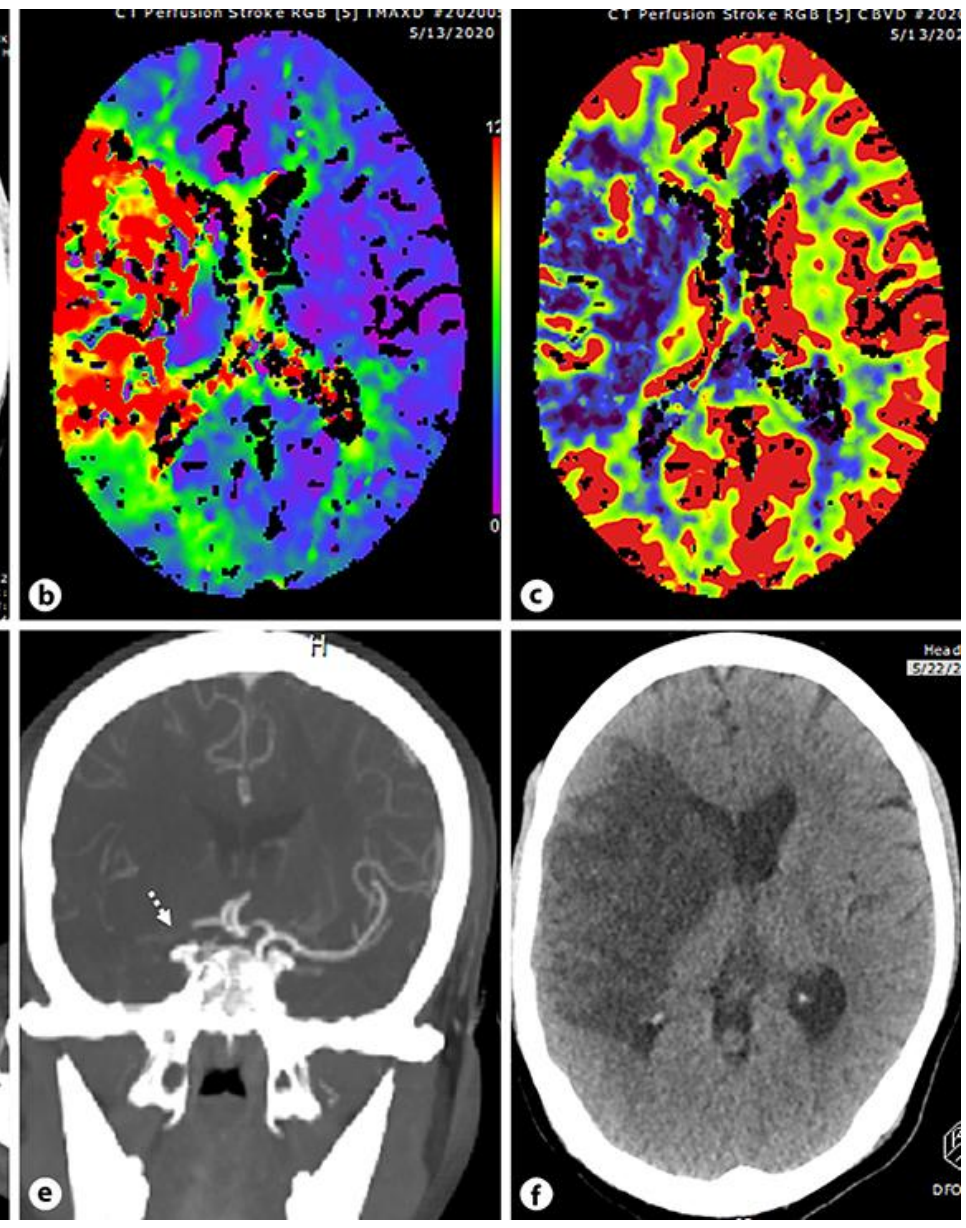

Fig. 1. a Axial non-contrast CT section of the head shows established infarct in the right basal ganglia and frontal lobe. b, c Axial $\mathrm{T}_{\max }$ and CBV perfusion maps demonstrate large right middle cerebral artery territory matched defect. $\mathbf{d}$ Coronal CTA reconstruction of the neck reveals occlusion of the right proximal CCA (white arrow). e Coronal CTA reconstruction of the head shows occlusion of the right terminal ICA (white dotted arrow). f Follow-up non-contrast axial CT scan of the head shows large right MCA territory infarct. 


\section{Case Reports in Neurology}

\begin{tabular}{l|l}
\hline Case Rep Neurol 2020;12:321-328 \\
\hline DOI: 10.1159/000511179 & $\begin{array}{l}\text { C 2020 The Author(s). Published by S. Karger AG, Basel } \\
\text { www.karger.com/crn }\end{array}$ \\
\hline
\end{tabular}
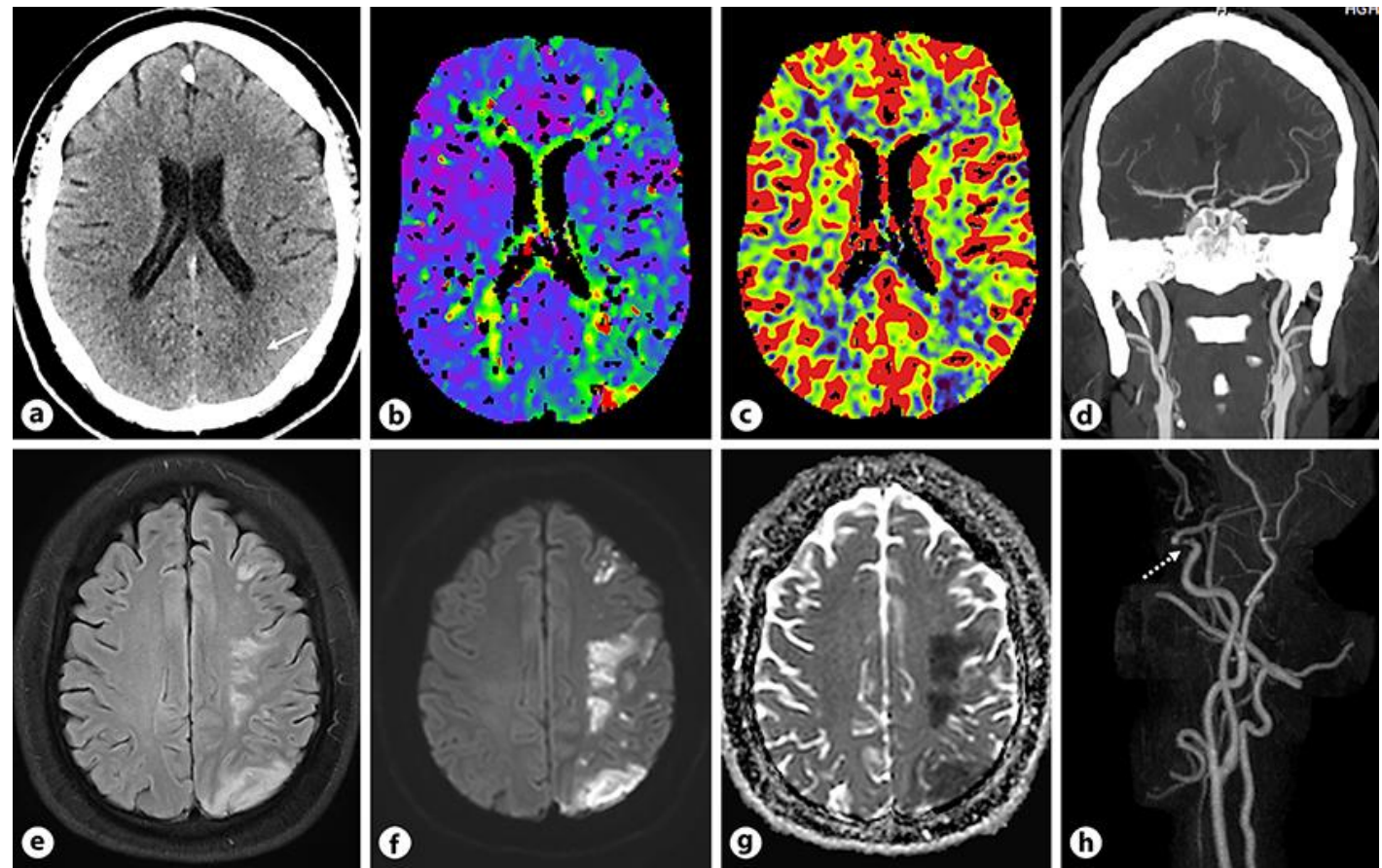

Fig. 2. a Axial non-contrast CT section of the head shows early ischemic changes in the left posterior parietal lobe along the MCA-PCA watershed zone (white arrow). b, c Axial $\mathrm{T}_{\max }$ and CBV perfusion maps demonstrate matched defect in the left posterior parietal lobe. $\mathbf{d}$ Coronal CTA reconstruction of the head reveals patent intracranial arteries. e Axial FLAIR image of the head demonstrates multiple patchy areas of increased signal in the left frontoparietal lobe along the watershed zone. $\mathbf{f}, \mathbf{g}$ Axial DWI and ADC map show multiple acute infarcts in the left frontoparietal lobe. $\mathbf{h}$ Post contrast MRA 3D reconstruction of the neck and head reveals focal moderate to severe stenosis in the left distal cavernous ICA (dotted white arrow). 


\section{Case Reports in Neurology}

\begin{tabular}{l|l}
\hline Case Rep Neurol 2020;12:321-328 \\
\hline DOI: 10.1159/000511179 & $\begin{array}{l}\text { (c) 2020 The Author(s). Published by S. Karger AG, Basel } \\
\text { www.karger.com/crn }\end{array}$ \\
\hline
\end{tabular}
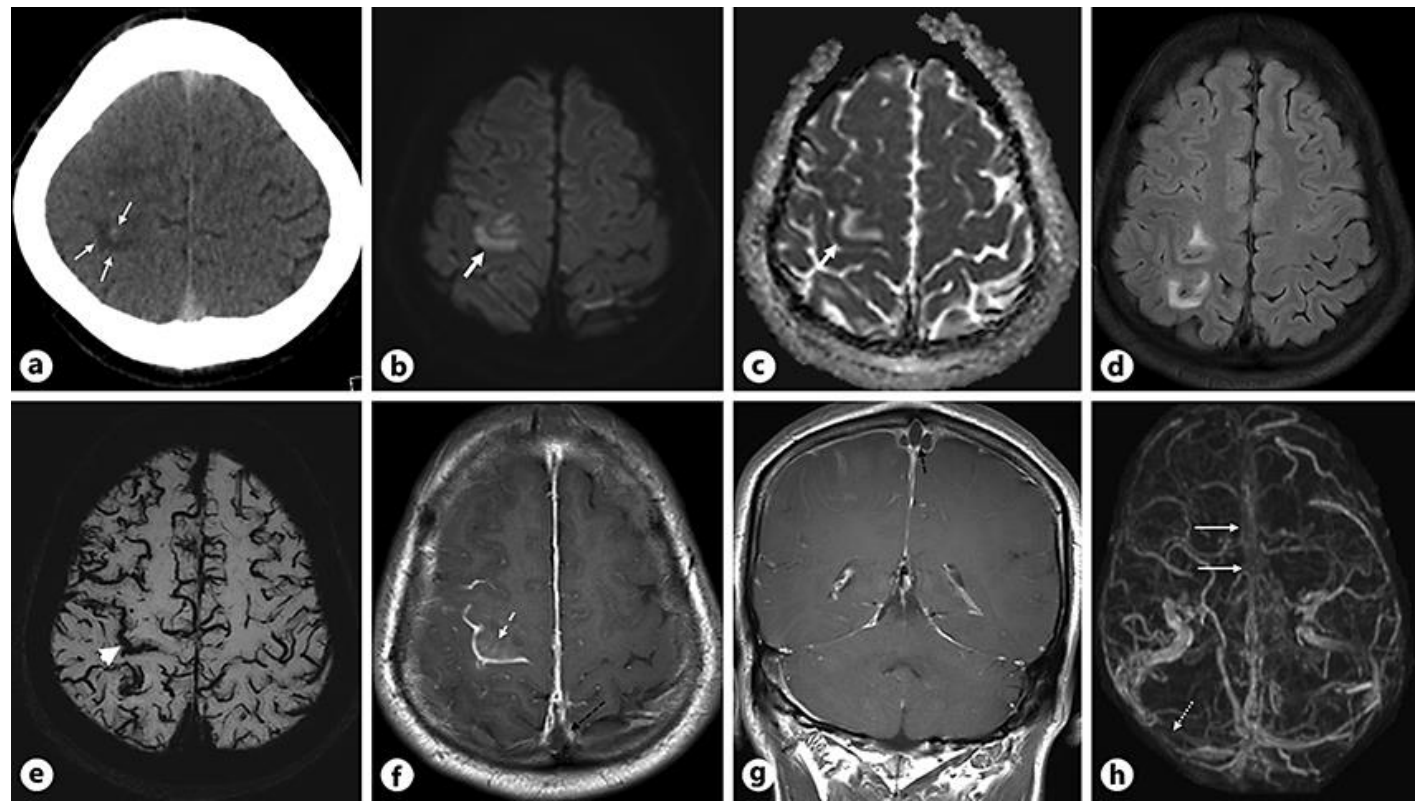

Fig. 3. a Axial non-contrast CT section of the head shows hemorrhagic infarcts in the right high frontal lobe (white arrows). b, c Axial DWI and ADC map demonstrate venous infarct in the right high frontal lobe (thick white arrow). d Axial FLAIR image reveals patchy hyperintensity in the right high frontal lobe. e Axial SWI image shows prominent cortical veins suggesting venous congestion and gyral microhemorrhage in the right precentral gyrus (white arrowhead). f, $\mathbf{g}$ Axial and coronal T1W post contrast images demonstrate thrombus in the superior sagittal sinus (dashed black arrow) and enhancement in the right precentral gyrus (white dashed arrow). $\mathbf{h}$ Post contrast MRV 3D reconstruction shows non visualization of the superior sagittal sinus (white arrows) and right transverse sinus (dotted white arrow). 